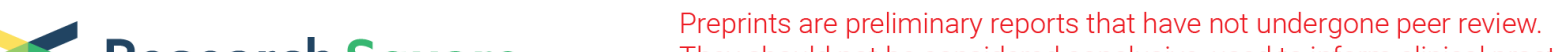 Research Square
or referenced by the media as validated information.
}

\section{The $532 \mathrm{Nm}$ Laser Treatment Promotes the Proliferation of Tendon- Derived Stem Cells and Up- Regulates Nr4a1 to Stimulate Tenogenic Differentiation}

\section{Ming Li}

Department of Plastic and Reconstructive Surgery, Shanghai Ninth People's Hospital, School of Medicine, Shanghai Jiao Tong University, Huangpu, Shanghai 200011

\section{Yi-Ming Zhu}

Department of General Surgery, Shanghai Ninth People's Hospital, School of Medicine, Shanghai Jiao Tong University, Huangpu, Shanghai 200011

\section{Qing Pei}

Department of Plastic and Reconstructive Surgery, Shanghai Ninth People's Hospital, School of Medicine, Shanghai Jiao Tong University, Huangpu, Shanghai 200011

\section{Yu-Hao Deng}

Department of Orthopedic Surgery, Shanghai Sixth People's Hospital, Shanghai Jiao Tong University, Xuhui, Shanghai 200233

\section{Tao Ni ( $\square$ nitao8888@yeah.net)}

Department of Plastic and Reconstructive Surgery, Shanghai Ninth People's Hospital, School of Medicine, Shanghai Jiao Tong University, Huangpu, Shanghai 200011

\section{Research Article}

Keywords: LLLT, tendon repairing, TDSCs, tenogenic differentiation, Nr4a1.

Posted Date: November 3rd, 2021

DOl: https://doi.org/10.21203/rs.3.rs-960303/v2

License: (c) (1) This work is licensed under a Creative Commons Attribution 4.0 International License. Read Full License 


\section{Abstract}

Background: The combination of low-level laser therapy (LLLT) and stem cell transplantation with tendon-derived stem cells (TDSCs) as seed cells provides a new treatment strategy for tendon injury. Nevertheless, the effect of LLLT on the biological behavior of TDSCs and its internal mechanisms remain unclear. This study aimed to verify the effect of LLLT with a wavelength of $532 \mathrm{~nm}$ on the proliferation and differentiation of TDSCs of Sprague-Dawley (SD) rats.

Methods: TDSCs were isolated from Achilles tendons of SD rats and identified by cell morphology and flow cytometric analysis. Energy density gradient experiment was performed to determine the ideal energy. Then TDSCs were treated with LLLT using a wavelength of $532 \mathrm{~nm}$ at a fluence of $15 \mathrm{~J} / \mathrm{cm}^{2}$. Cell response after irradiation was observed at 6,12 and 24 hours to ascertain cell morphology and cell proliferation. The RNA expression levels of the key genes of TDSCs differentiation, including Scx, Tnmd, Mkx and Dcn, PPARy, Sox9 and Runx2, were detected by RT-PCR. Then gene chip microarray was used to detect the expression of differential genes after $532 \mathrm{~nm}$ laser intervention in TDSCs, and the target genes were screened out to verify the role of target genes in this process.

Results: When the $532 \mathrm{~nm}$ laser energy density was $15 \mathrm{~J} / \mathrm{cm}^{2}$, the proliferation capacity of TDSCs was improved $(2.73 \pm 0.24$ vs. $1.81 \pm 0.71, P<0.05)$, and the expression of genes related to tenogenic differentiation of TDSCs was significantly increased $(P<0.01)$, showing the potential of tenogenic differentiation. After RNA-seq and bioinformatics analyses, we speculated that Nr4a1 was involved in the tenogenic differentiation process of TDSCs regulated by $532 \mathrm{~nm}$ laser treatment. Subsequent experiments confirmed that $\mathrm{Nr} 4 \mathrm{a} 1$ regulated the expression of the tenogenic differentiation genes scleraxis (Scx) and tenomodulin (Tnmd) in TDSCs, affecting the process.

Conclusion: A $532 \mathrm{~nm}$ laser with $15 \mathrm{~J} / \mathrm{cm}^{2}$ regulated the process of TDSC proliferation and tenogenic differentiation by up-regulating $\mathrm{Nr} 4 \mathrm{a} 1$, which could accelerate tendon healing.

\section{Background}

With population aging and the promotion of sports, the number of people suffering from tendon injuries is growing, with such injuries affecting younger and younger populations. According to the epidemiological statistics, tendon or ligament injuries account for $45 \%$ of musculoskeletal injuries in the US, and the incidence of tendon injury is more than $40 \%$ in baseball players and long-distance runners [1]. Surgical treatment, which is the main treatment method for tendon injury, mainly involves the combination of tendon suture and external fixation [2]. However, problems remain concerning postoperative tendon mechanical strength, scar tissue hyperplasia, tissue adhesion, etc. [3]. Therefore, identifying a tendon repair strategy with less damage and high efficiency is of urgent importance.

Over recent years, stem cell transplantation in tissue engineering has become widely used to treat tendon injury. Mesenchymal stem cells (MSCs), which have a wide range of sources, are relatively simple to obtain. These cells also have the potential for rapid proliferation and multidirectional differentiation 
under specific conditions, and are thus important seed cells for tissue engineering [4]. For example, adipose-derived stem cells (ADSCs) have been applied in tendon repair [5]. Tendon-derived stem cells (TDSCs) not only have the characteristics of mesenchymal stem cells, comparable to the more commonly-used seed cells such as bone marrow stem cells (BMSCs), but can also highly express tendonrelated genes and proteins, such as scleraxis (Scx), tenomodulin (Tnmd), and mucin C, and have a special tendency to differentiate into tendon cells $[6,7]$. Therefore, numerous researchers have explored the application of TDSCs in the treatment of injured tendons [8]. Some researchers transplanted TDSCs into a rat model of patella tendon injury and found that, compared with the control group, the repaired tendon showed a more orderly arrangement of fibrous tissue and stronger biomechanics after 8 weeks [9]. Still, there are some practical problems in applying stem cells in clinical treatment, such as unclear differentiation mechanism, maintenance of the differentiation ability of stem cells, and difficulty in controlling the direction of differentiation [6].

Low level laser therapy (LLLT) is a non-invasive phototherapy method that uses a laser to biologically stimulate cells without thermal stimulation, affecting the biological behavior of cells and accelerating tissue repair and reconstruction [10]. Since the discovery of lasers in the 1960s, LLLT has shown great prospects for clinical application, such as in wound healing, androgenetic alopecia, muscle pain relief, and regulation of inflammation, because of its advantages of causing only slight damage, its strong operability, and nontoxic side effects [11, 12]. Studies have shown that LLLT can regulate the proliferation and differentiation of MSCs. Tani et al. reported that a $635 \mathrm{~nm}$ laser regulates differentiation of BMSCs into osteoblasts by activating the AKT signaling pathway, which enhances cytoskeletal construction and bone mineralization formation patterns [13]. The effects of LLLT of different wavelengths and energy densities on MSCs are different. In a study comparing the effects of a $630 \mathrm{~nm}$ laser and an $810 \mathrm{~nm}$ laser on the proliferation of ADSCs at energy densities of $0.6 \mathrm{~J} / \mathrm{cm}^{2}, 1.2 \mathrm{~J} / \mathrm{cm}^{2}$ and $2.4 \mathrm{~J} / \mathrm{cm}^{2}$, it was found that a $630 \mathrm{~nm}$ laser with energy density of $1.2 \mathrm{~J} / \mathrm{cm}^{2}$ and an $810 \mathrm{~nm}$ laser of $2.4 \mathrm{~J} / \mathrm{cm}^{2}$ had the strongest effect on the activity of ADSCs [14]. Numerous studies have shown that LLLT at a specific wavelength and appropriate energy density activated MSCs and promote their proliferation and differentiation in vitro.

Our research group is devoted to exploring the mechanism of a $532 \mathrm{~nm}$ laser and its effect on tendon repair. In our previous study, we used an optical treatment method called photochemical tissue bonding (PTB) which employed a $532 \mathrm{~nm}$ laser and the photosensitizer Rose Bengal (RB) to treat Achilles tendon injury in rats. Our results revealed that such an approach promoted repair of the injured tendon, and the biomechanical strength of the tendon was also significantly enhanced. Furthermore, study of the mechanism revealed that the continuous low release level of reactive oxygen (ROS) in tendon cells treated with a $532 \mathrm{~nm}$ laser activates the RhoA/NF-KB pathway, thereby promoting the proliferation and migration of tendon cells and accelerating tendon healing $[15,16]$. Most researchers believe that TDSCs have an important role in repairing injured tendon $[17,18]$. Whether the proliferation and differentiation of TDSCs can be regulated to promote the repair of the injured tendon during the process of $532 \mathrm{~nm}$ laserinduced repair of injured Achilles tendon remains to be elucidated. 
Accordingly, the current study aimed to isolate, identify, and culture TDSCs from SD rats. Additionally, after identifying a reasonable energy density of TDSCs irradiated by a $532 \mathrm{~nm}$ laser, the influence of the $532 \mathrm{~nm}$ laser on the proliferation and differentiation of TDSCs was investigated. RNA sequencing (RNAseq) was used to detect differentially-expressed genes in TDSCs after $532 \mathrm{~nm}$ laser irradiation, and the key genes were screened and verified by bioinformatics analysis so as to explore the possible mechanism via which the $532 \mathrm{~nm}$ laser regulated the proliferation and differentiation of TDSCs.

\section{Materials And Methods}

\section{TDSC isolation and cell culture}

Achilles tendons (AT) were harvested from one of the hindlimbs of Sprague-Dawley (SD) rats, anesthetized with $0.5 \%$ pentobarbital sodium $(0.3 \mathrm{~mL} / 100 \mathrm{~g}$, Sigma-Aldrich) by intraperitoneal administration. Pieces of the ATs $0.5 \times 1.0 \mathrm{~cm}^{2}$ were isolated, cut into $0.25 \mathrm{~cm}^{3}$ pieces and digested with type I collagenase ( $2 \mathrm{mg} / \mathrm{mL}$; Sigma-Aldrich) in DMEM supplemented with $2 \%$ fetal bovine serum for $16 \mathrm{~h}$ at $37^{\circ} \mathrm{C}$ and collected using a $70-\mathrm{mm}$ cell strainer. PBS was used to wash the cells by centrifugation at $800 \times g$ for $5 \mathrm{~min}$, then reseed the cells at $1 \times 10^{4} \mathrm{cells} / \mathrm{cm}^{2}$ in monolayer cultures in complete high glucose DMEM (HG-DMEM) supplemented with $20 \%$ fetal bovine serum, $100 \mathrm{mg} / \mathrm{mL}$ streptomycin, and $100 \mathrm{U} / \mathrm{mL}$ penicillin. After $24 \mathrm{~h}$ of initial culture, transfer the nonadherent cells to fresh culture flasks to exclude the rapidly-adherent, fibroblast-like cells. At day 7, TDSCs were trypsinized and mixed together as passage 0 , after which they were passaged four or five times before use for experiments.

\section{Flow cytometry assay}

TDSCs at passage 4 were harvested by digestion with $0.25 \%$ trypsin/ ethylenediaminetetraacetic acid (EDTA) as described above. $1 \mathrm{mg}$ of fluorescein isothiocyanate (FITC) fluorescent dyes conjugated with anti-rat monoclonal antibodies (CD44, CD45, and CD90) was used to incubate around $1 \times 10^{6}$ cells separated by centrifugation, after that $4 \%$ paraformaldehyde was used to fix the cells at room temperature for 20 minutes. Then $200 \mu \mathrm{L} \mathrm{PBS} \mathrm{(} \mathrm{pH}=7.4$ ) was used to wash the cells, after that, cells were removed from the fixing solution, and resuspended in PBS for flow cytometry. FC 500 Flow Cytometry Analyzer (Beckman Coulter, Brea, USA) was used to perform the analysis of the phenotypic results.

\section{Laser Intervention Method}

A $532 \mathrm{~nm}$ Nd:YAG laser (Oculight; Iridex, Mountain View, USA) with a diameter of $5 \mathrm{~mm}$ was used. During the irradiation, the distance between the laser emitter and the cell layer was kept at $6 \mathrm{~cm}$ for all cell groups. Sterile foil was used to create an enclosed space to prevent interference caused by light dispersion and refraction. After irradiation, continue to incubate the cells, and the culture medium was replaced every $1-2$ days.

\section{Cell Titer-glo (Ctg) Assay}


96-well plates were used to seed the stem cells at $1 \times 10^{4} \mathrm{cells} /$ well, and then the cells were assigned to one of seven energy density laser groups $\left(0 \mathrm{~J} / \mathrm{cm}^{2}, 1.5 \mathrm{~J} / \mathrm{cm}^{2}, 3 \mathrm{~J} / \mathrm{cm}^{2}, 6 \mathrm{~J} / \mathrm{cm}^{2}, 9 \mathrm{~J} / \mathrm{cm}^{2}, 15 \mathrm{~J} / \mathrm{cm}^{2}\right.$ and $24 \mathrm{~J} / \mathrm{cm}^{2}$ ). The irradiation times for these seven groups were: $0 \mathrm{~s}, 30 \mathrm{~s}, 60 \mathrm{~s}, 2 \mathrm{~min}, 3 \mathrm{~min}, 5 \mathrm{~min}$, and 8 min, respectively. The CTG assay was performed at 24 and $48 \mathrm{~h}$ after a single exposure.

\section{Crystal Violet Assay}

Cells were seeded into 96 -well plates at $1 \times 10^{4}$ cells/well and cultured at $37^{\circ} \mathrm{C}$ in a constant temperature incubator. After 6,12 , or $24 \mathrm{~h}$, remove the culture medium, and $4 \%$ paraformaldehyde (PFA) solution was used to fix cells for $15 \mathrm{~min}$ at room temperature (RT), after that, cells were washed with PBS, and then stain each well with $100 \mu \mathrm{L}$ of $0.2 \%$ Crystal Violet solution in PBS for 15 min at RT. Deionized water was used to wash the dye solution from the plates, and the dye was then solubilized in $100 \mu \mathrm{L}$ of $1 \%$ sodium dodecyl sulfate (SDS) solution in PBS. A microplate reader was used to measure the optical density (OD) at the emission wavelength of $570 \mathrm{~nm}$ to compare the proliferation of the two groups of cells.

\section{Quantitative Real-time Reverse Transcription-polymerase Chain Reaction (Rt-pcr)}

The differentiation-related gene expression after 24 and $48 \mathrm{~h}$ of $532 \mathrm{~nm}$ laser single irradiation were analyzed by RT-PCR. An RNA purification kit (Corning, Corning, NY, USA) was used to extract total RNA. Reverse transcription (RT) step was conducted using a Prime Script RT Reagent Kit (Takara Bio Inc., Shiga, Japan) to reverse transcribe RNA into cDNA. Real-time PCR was quantified using SYBR Premix Ex Taq (Takara Bio Inc.) in a Light Cycler ${ }^{\circledR} 96$ System (Roche, Basel, Switzerland). GAPDH was set as an internal reference. The specific primers for differentiation-related genes (Invitrogen, Carlsbad, CA, USA) used in this study are listed in Table 1. The result was expressed as the relative expression ratio of the target sample and the control group for each sample, calculated using the $2^{-\triangle \Delta C T}$ method.

\section{Western Blotting}

Lysis Buffer (RIPA, Beyotime, Shanghai, China) was used to collect total protein from cultured cells, then the proteins were supplemented with $1 \%$ protease inhibitor (Roche Applied Science), and a total of $40 \mu \mathrm{g}$ protein were loaded for electrophoresis. Then a 10\% SDS polyacrylamide gel electrophoresis (SDS-PAGE) was prepared to separate the proteins. After that, the proteins were transferred to a nitrocellulose membrane (Merck Millipore). Membranes were blocked for $1 \mathrm{~h}$ with $5 \%$ nonfat milk at RT, and blots were probed with the following antibodies: anti-Nr4a1 (1:1,000, ab13851, Abcam, Cambridge, UK), anti-Scx (1:1,000, ab185940, Abcam), and anti-tenomodulin (1:1,000, ab203676, Abcam) at $4^{\circ} \mathrm{C}$ overnight. The membrane was incubated with anti-rabbit IgG $(1: 1,000$, ab205718, Abcam) for $1 \mathrm{~h}$ at RT after washing in Tris-buffered saline containing Tween. 


\section{Gene Chip Microarray Assay And Analysis}

After $48 \mathrm{~h}$ of $532 \mathrm{~nm}$ single laser irradiation, cells of $532 \mathrm{~nm}$ laser group and control unirradiated cells were dissolved in Trizol (Life Technologies, USA) to obtain total RNA isolation. The EXON Gene Chip instrument (Affymetrix, Thermo Fisher Scientific) was used to quantified RNA concentration, and an Agilent Bioanalyzer 2100 (Agilent Technologies, USA) was used to assess RNA integrity. Raw data were extracted by the Gene Chip Command Console software version 4.0 (Affymetrix) according to the manufacturer's instructions. The Gene software version 13.1 (Agilent Technologies) was used to perform Basic analysis. Expression Console software version 1.3.1 (Affymetrix) was used to perform RNA normalization. Ultimately, Kyoto Encyclopedia of Genes and Genomes (KEGG) pathway and gene ontology (GO) analysis were applied to clarify the molecular functions of up-regulated genes and relevant pathways.

\section{Tendon Injury Model}

Thirty-six SD rats (male, 6-weeks-old) were obtained from the Laboratory Animal Services Centre. All the animals were kept in an environment with a temperature of $25 \pm 1{ }^{\circ} \mathrm{C}$, a relative humidity of $65 \pm 5 \%$, and a light/dark cycle of 12/12 hr. Animals were given water and sterilized food ad libitum. All animal studies (including the rat euthanasia procedure) were carried out in compliance with the regulations and guidelines of Shanghai Jiao Tong University institutional animal care, the AAALAC and the IACUC.

Thirty-six rats were divided into two groups: a control group and a $532 \mathrm{~nm}$ laser group. For the tendon injury model, we adopted a rat model of Achilles-tendon injury following a previously-reported method [19]. The Achilles tendon was separated from the plantaris and soleus tendons and injury were surgically induced by semi-cutting, followed by primary suture repair. For rats in the laser group, the tendon was irradiated with a $532 \mathrm{~nm}$ laser and then sutured, while for those in the control group the tendons were directly sutured. Tendon tissue samples were collected 7 days after modeling.

\section{Hematoxylin And Eosin (H\&e) Staining}

$4 \%$ paraformaldehyde was prepared to fix Pieces of tendons, then the samples were dehydrated with $30 \%$ sucrose and embedded in OCT (Sakura Finetek, Torrence, USA). Before section, the samples were frozen at $-80^{\circ} \mathrm{C}$, then cut cryosections at $5 \mu \mathrm{m}$ thickness. After that, H\&E (Sakura Finetek) was used to stain the samples. An upright microscope (Olympus, Tokyo, Japan) was used to image the samples.

\section{Immunohistochemistry}

The specimens of the tendon injury model were divided into two groups for histological tests. The tissues were fixed in $4 \%$ paraformaldehyde solution, dehydrated with a series of concentration gradient ethanol, 
and then embedded in paraffin. Sections were stained as 5 mm-thick sections with Anti-Nr4a1 (1:1,000, ab13851, Abcam). After that, $5 \%$ bovine serum albumin was used to block nonspecific reactive sites, then incubate the slides overnight at $4^{\circ} \mathrm{C}$ with anti-rat targeted antibodies at 1:200 to 1:500 dilutions and then conjugated with goat anti-rabbit IgG (1:1500; Santa Cruz Biotechnology, USA) secondary antibody in the dark at RT for $1 \mathrm{~h}$. Then, the sections were stained with 3,3'-diaminobenzidine and finally counterstained with hematoxylin.

\title{
Cell Transfection
}

pCDNA3.1 (+) was used as cloning vector of the Nr4a1 coding sequence. The primers were as follows:

\author{
F: ATGCGATTCTGCAGCTCTTCC, \\ R: GGGTGGTATTGTCGTAGTAGAAGG.
}

TDSCs $\left(5 \times 10^{3}\right.$ cells/well) were plated into 6-well plates and transfected with either pCDNA3.1(+)-Nr4a1 or blank pCDNA3.1 (+) vector. Lipofectamine 2000 reagent (Invitrogen) was used to perform the transfection according to the manufacturer's instructions. After $6-8 \mathrm{~h}$, TDSCs were washed and cultured for $24 \mathrm{~h}$ in complete medium.

\section{Statistical analysis}

All experiments were carried out at least three times and data were expressed as means \pm standard deviation (SD). SPSS 13.0 (IBM, Armonk, NY, USA) was used to analyze statistics. Differences among more than two experimental groups were evaluated by one-way ANOVA. $P \leq 0.05$ was considered statistically significant. Image $\mathrm{J}$ and GraphPad Prism software were used for plotting calculations.

\section{Results}

\section{Isolation and characterization of TDSCs}

Cells were isolated from Achilles tendons of SD rats and formed initial colonies when inoculated into culture dishes at low density. The cell morphology was cobblestone-like, and the cells had clone-forming ability after subculture (Fig. 1a), which was in accordance with other reports [20]. In addition, the separated cells showed homogeneous spindle-shaped or fibroblastic features, and the morphology remained stable for several generations (Fig. 1b). Furthermore, when compared with isotype control by flow cytometric analysis, $95.3 \%$ of cells were positive for CD44 (Fig. 1C), and $97.6 \%$ were positive for CD90 (Fig. 1e), but they were negative for the leukemia cell marker CD45 (Fig. 1d). These data demonstrated that the isolated cells had characteristics of stem cells indicating that they were TDSCs.

The energy density gradient experiment of TDSCs was regulated by the $532 \mathrm{~nm}$ laser. 
The CTG fluorescent cell viability test is a method that indirectly reflects cell viability by measuring the synthesis of adenine nucleoside triphosphate (ATP) in cells. We used CTG to measure the OD value of TDSCs at 12 and $24 \mathrm{~h}$ after a single $532 \mathrm{~nm}$ laser irradiation. The experimental results (Fig. 2) revealed that when the energy density of the $532 \mathrm{~nm}$ laser exceeded $6 \mathrm{~J} / \mathrm{cm}^{2}$, the cell activity of TDSCs in each group significantly increased compared with that in the control group $(P<0.01)$, and the cell activity of TDSCs also increased with the increase of energy density. However, when an energy density of $15 \mathrm{~J} / \mathrm{cm}^{2}$ or $24 \mathrm{~J} / \mathrm{cm}^{2}$ was used, there was no significant difference in the cell viability of TDSCs in the two groups $(P>0.05)$. Therefore, we selected the $15 \mathrm{~J} / \mathrm{cm}^{2}$ group for subsequent study.

\section{The $532 \mathrm{~nm}$ laser stimulated the proliferation of TDSCs.}

To investigate the impact of the $15 \mathrm{~J} / \mathrm{cm}^{2} 532 \mathrm{~nm}$ laser on the proliferative ability of TDSCs, we used the Crystal Violet staining method to analyze the number of cells in the control group and the $532 \mathrm{~nm}$ lasertreated group at 6, 12, and $24 \mathrm{~h}$ (Fig. 3a). When the cells were cultured for $6 \mathrm{~h}$, the TDSCs of the two groups were adherent to the wall, and the cell inoculation density was basically the same. At $24 \mathrm{~h}$, the cell morphology was polygonal, and the number of cells in the $532 \mathrm{~nm}$ laser group significantly increased. After dissolving the Crystal Violet with SDS, the OD values of the two groups were measured (Fig. 3b). This showed that the OD value of the $532 \mathrm{~nm}$ laser group was significantly higher than the control group $\left(2.73 \pm 0.24\right.$ vs. $\left.1.81 \pm 0.71,{ }^{\star} P<0.05\right)$. Thus the $532 \mathrm{~nm}$ laser at $15 \mathrm{~J} / \mathrm{cm}^{2}$ can promoted the proliferation of TDSCs.

\section{Irradiation with a $532 \mathrm{~nm}$ laser regulated the differentiation of TDSCs.}

To investigate the effect of $532 \mathrm{~nm}$ laser irradiation on the differentiation ability of TDSCs, RT-PCR was used to analyze the RNA expression levels of the key genes of TDSC differentiation, Scx, Tnmd, Mkx, and Dcn (related to tendinous differentiation), PPARY (adipogenic marker gene), Sox 9 (chondrogenic marker gene) and Runx2 (osteogenic marker gene). Our data showed that at 24 and $48 \mathrm{~h}$, the expression levels of Scx and Tnmd genes in TDSCs in the $532 \mathrm{~nm}$ laser group were significantly increased compared with those in the control group, showing a statistically significant difference $\left({ }^{\star *} P<0.01\right)$ (Fig. 4a, b). In contrast, the markers of adipogenic, chondrogenic, and osteogenic differentiation did not significantly change $(P>0.05)$ (Fig. 4c, d), which indicated that after $532 \mathrm{~nm}$ laser intervention, the tenogenic differentiation-related markers of TDSCs were highly expressed, inducing the cells to differentiate into tendon cells.

\section{The Nr4a1 and the TGF- $\beta$ signaling pathway is involved in the process of TDSC differentiation regulated by $532 \mathrm{~nm}$ laser irradiation.}

To investigate the mechanism of $532 \mathrm{~nm}$ laser irradiation in regulating the differentiation process of TDSCs, gene expression was analyzed in TDSCs collected from the laser-treated group and the control group using gene chip microarray (Fig. 5a). GO and KEGG pathway analyses were performed to confirm the roles of up-regulated genes in molecular functions and pathways. Skeletal muscle tissue 
development and skeletal muscle cell differentiation were both enriched in the biological process category of GO analyses (Fig. 5b). In addition, the TGF- $\beta$ signaling pathway was enriched in KEGG pathway analysis of up-regulated genes (Fig. 5c).

Among the 795 differentially-expressed genes identified by gene chip microarray, 15 genes that were closely related to the signaling pathways enriched by GO analysis and KEGG pathway analysis included Nr4a1, Tnmd, Scx, Fos, Egr1, and Btg2. These genes related to the TGF- $\beta$ pathway showed a significant difference in expression between the two groups. According to the literature review, among these genes, $\mathrm{Nr} 4 \mathrm{a} 1$ is closely related to TGF- $\beta$, and it has been reported that Nr4a1 induces cell differentiation [21, 22]. Therefore, we focused on the role of Nr4a1 in the differentiation of TDSCs regulated by $532 \mathrm{~nm}$ laser irradiation.

\section{The expression of Nr4a1 was increased in injured tendons of the rat model after $532 \mathrm{~nm}$ laser intervention.}

H\&E staining was used to observe the repair of tendon tissue in the two groups (Fig. 6a). At $7 \mathrm{~d}$, the damaged tendon fibers in the control group were arranged in a disordered manner, with irregular cell morphology and more "vacuole-type" structures. At $14 \mathrm{~d}$, in the $532 \mathrm{~nm}$ laser group, the structure of the Achilles tendon was denser, the arrangement was orderly, and the infiltration of inflammatory cells was lower. The results showed that the repair effect in the $532 \mathrm{~nm}$ laser group was better than that of the control group.

To verify whether Nr4a1 was expressed in tendon tissues after $532 \mathrm{~nm}$ laser intervention, the expression of Nr4a1 in Achilles tendon tissue was analyzed by immunohistochemical staining. The results revealed that the expression of $\mathrm{Nr} 4 \mathrm{a} 1$ in Achilles tendon tissue was significantly increased in the laser-treated group compared with the control group (Fig. 6b, 6c).

\section{Nr4a1 inhibited the expression of Scx and Tnmd to regulate the differentiation of TDSCs induced by 532 $\mathrm{nm}$ laser irradiation.}

To preliminarily explore the role of Nr4a 1 in the differentiation of TDSCs induced by $532 \mathrm{~nm}$ laser irradiation, the expression of the Nr4a1 gene in TDSCs of the $532 \mathrm{~nm}$ laser group and the expression changes of Scx and Tnmd in TDSCs of the transfected Nr4a1 siRNA $532 \mathrm{~nm}$ laser group was analyzed by RT-PCR. The results showed that Nr4a1 expression after $532 \mathrm{~nm}$ laser irradiation of TDSCs was significantly increased compared with the control group (2.74-Fold, $P<0.01$ ) (Fig. 7a). The expression levels of Scx and Tnmd genes in the Nr4a1 siRNA+532 nm laser group were significantly down-regulated compared with the $532 \mathrm{~nm}$ laser group $(P<0.05)$ (Fig. 7b). The expression levels of the proteins Scx and Tnmd related to tendon differentiation in TDSCs in the $532 \mathrm{~nm}$ laser group were significantly increased compared with the control group $(P<0.05)$, while the expression levels of proteins Scx and Tnmd in the $\mathrm{Nr} 4 a 1$ siRNA $^{+} 532 \mathrm{~nm}$ laser group were significantly decreased compared with the $532 \mathrm{~nm}$ laser group ( $P$ $<0.05$ ) (Fig. 7c and 7d). These results show that inhibiting the expression of Nr4a1 also blocked the expression of Scx and Tnmd. 


\section{Discussion}

Over recent years, low-level laser therapy (LLLT) has achieved good efficacy in inhibiting inflammation, relieving pain, and promoting injury repair. Some researchers used an $808 \mathrm{~nm}$ laser of $6.38 \mathrm{~J} / \mathrm{cm}^{2}$ to irradiate the wound in a rat injury model, and the results showed that the wound surface contraction rate of the $808 \mathrm{~nm}$ laser group was faster than that of the control group at 2 weeks after injury, while the average wound healing rate was significantly higher [23]. The role of LLLT in the repair of tendon injury has attracted increasing attention. In our previous study, we used a $532 \mathrm{~nm}$ laser combined with the photosensitizing agent Rose Bengal (RB) to treat an Achilles tendon injury in rats and observed that this treatment significantly promoted the repair of the injured Achilles tendon. Further studies revealed that the tendon cells treated with the $532 \mathrm{~nm}$ laser exhibited sustained and low release of reactive oxygen species (ROS), which could activate the RhoA/NF-B pathway, promote the proliferation and migration of tendon cells, and accelerate tendon healing $[15,16]$. Therefore, in this study, we wanted to investigate whether a $532 \mathrm{~nm}$ laser promoted the repair of injured tendon by regulating the proliferation and differentiation of TDSCs.

Previous studies have confirmed that LLLT promoted the proliferation of vascular endothelial cells, osteoblasts, and other cell types. Some researchers believe that the main reason why LLLT promotes cell proliferation is that the colored groups in mitochondria absorb and convert the light energy from LLLT irradiation into chemical energy, which is stored and utilized in the form of ATP, so as to enhance cell proliferation and activation [24]. Altan et al. irradiated the damaged upper incisors of mice with a laser of $15 \mathrm{~J} / \mathrm{cm}^{2}$ at $830 \mathrm{~nm}$ wavelengths. After 1 week, they found increased neovascularization, significant proliferation of osteoblasts and osteoclasts, and accelerated bone reconstruction [25]. The regulation and differentiation induced by LLLT is closely related to the energy density and wavelength of the laser [26]. In this experiment, we investigated the energy density and found that the proliferation capacity of TDSCs was significantly enhanced when the energy density exceeded $6 \mathrm{~J} / \mathrm{cm}^{2}$. At the same time, we found no significant difference in proliferation capacity between the groups treated with energy densities of 15 $\mathrm{J} / \mathrm{cm}^{2}$ and $24 \mathrm{~J} / \mathrm{cm}^{2}$. Therefore, we chose $15 \mathrm{~J} / \mathrm{cm}^{2}$ as the appropriate energy density for subsequent studies.

Scx and Tnmd are not only important transcription factors expressed in TDSCs during tendon differentiation but also key genes related to the formation and development of tendons [27]. Nicholas et al. pointed out that when gene knockout technology was used to construct Scx-deficient mice, their tendon tissues were naturally deficient due to the decrease of tendon matrix and disordered fiber arrangement, indicating the importance of Scx in the process of tendon formation [28]. TDSCs spontaneously express Scx and Tnmd. When TDSCs differentiate into adipocytes or chondrocytes, the expression of Scx and Tnmd are significantly decreased, while the expression of Scx and Tnmd are often increased during the differentiation of TDSCs into tendons and ligaments, thus indicating that Scx and Tnmd have a certain specific correlation with the differentiation of tendons [29]. Therefore, we used Scx and Tnmd as two observational indicators to judge the differentiation of TDSCs. RT-RCR and western blot detection showed that both the gene and protein levels of Scx and Tnmd of TDSCs at different phase 
points after $532 \mathrm{~nm}$ laser irradiation were significantly higher than those of the control group $(P<0.01)$, suggesting that a $532 \mathrm{~nm}$ laser could regulate the tendon differentiation of TDSCs.

Orphan nuclear receptor $N R 4 A 1$, a member of the early response gene family, also known as Nur77or $T R 3$, is widely expressed in a variety of tissues, including skin, muscle, and blood [30]. It is rapidly expressed under chemical and physical stimulation and specifically combines with the regulatory region of the target gene to exert its role in regulating gene transcription, thus participating in cell survival and apoptosis, energy metabolism, inflammatory response regulation, angiogenesis and remodeling, and other cellular biological behaviors [21,31]. Some studies have shown that Nr4a1 inhibited apoptosis by reducing the activity of caspase 3/caspase 8 [32]. Moreover, it regulates the expression of cell cycle genes and promotes cell proliferation and differentiation [33]. Some experiments found that in Nr4a1deficient mice, the apoptosis of bone-marrow-derived monocytes was accelerated, and their differentiation was inhibited [34]. However, the mechanism via which $\mathrm{Nr} 4 \mathrm{a} 1$ regulates cell differentiation is still unclear. By comparing the transcription levels of Nr4a1-deficient mice with those of normal mice, it was found that $\mathrm{Nr} 4 \mathrm{a} 1$ inhibited the differentiation of $\mathrm{T}$ cells into regulatory $\mathrm{T}$ cells by activating the mTOR/Akt pathway. Thus, Nr4a1 has an important role in regulating cell differentiation [35].

In this study, we found that Nr4a1 expression was significantly increased in TDSCs after $532 \mathrm{~nm}$ laser irradiation, through RNA sequencing technology (RNA-seq) and GO and KEGG analysis. Moreover, Nr4a1 was closely related to the skeletal muscle development pathway, and we believe that $\mathrm{Nr} 4 \mathrm{a} 1 \mathrm{has}$ an important role in this process. We used Nr4a1 siRNA to inhibit the expression of Nr4a1, which targeted $\mathrm{Nr} 4 \mathrm{a} 1$ by interfering with $\mathrm{Nr} 4 \mathrm{a} 1$ gene expression via mRNA degradation after transcription, resulting in translation blockage. Our results indicated that Nr4a1 siRNA inhibited the expression of the tenogenic differentiation-related genes Scx and Tnmd in TDSCs.

Our KEGG pathway analysis suggested that highly-enriched TGF pathways were activated during this process. There is a negative feedback loop between Nr4a1 and TGF- $\beta$ which jointly regulate fibrosis in tissues [22]. Some studies have pointed out that the TGF- $\beta$ signaling pathway was closely related to Scx, TGF- $\beta$ regulates the expression of Scx and Tnmd by activating Smad 2/3 and regulating the downstream Sox9 [36]. From the perspective of embryonal development, TGF- $\beta$ stimulates the differentiation of mesoderm cells towards the tendon-forming direction and inhibits chondrogenesis at the same time [37]. Considering the above, it is reasonable to speculate that Nr4a1 regulates the tenogenic differentiation factors Scx and Tnmd of TDSCs by regulating the TGF- $\beta$ signaling pathway. Further experiments are needed to verify this hypothesis.

\section{Conclusions}

In summary, we successfully isolated and identified tendon-derived stem cells (TDSCs) from SD rats in this study. After finding the ideal $532 \mathrm{~nm}$ laser energy density, the effect of a $532 \mathrm{~nm}$ laser on the proliferation and differentiation of TDSCs was verified. Then, bioinformatics analysis revealed that 532 $\mathrm{nm}$ laser-treated TDSCs exhibited high Nr4a1 expression. At the same time, by transfecting TDSCs with 
an Nr4a1 siRNA plasmid, we verified that Nr4a1 acted during $532 \mathrm{~nm}$ laser irradiation to induce TDSCs to differentiate into tendon and plays a role in the process. Meanwhile inhibiting the Nr4a1 expression of TDSCs obviously decreased the expression of the tendon differentiation markers Scx and Tnmd at the gene and protein levels in the $532 \mathrm{~nm}$ laser treatment group. Therefore, we speculated that $532 \mathrm{~nm}$ laser irradiation of TDSCs activated the early response gene $\mathrm{Nr} 4 \mathrm{a} 1$ to regulate the generation of tendon differentiation markers such as Scx and Tnmd, promoting the differentiation of TDSCs into tendon cells and thus promoting the repair of injured tendon. However, the specific intrinsic molecular mechanisms still need to be verified by further experiments.

\section{Abbreviations}

AAALAC

Association for Assessment and Accreditation of Laboratory Animal Care International AKT

AKT serine/threonine kinase 1

AT

Achilles tendons

BMSCs

Bone marrow stem cells

Btg2

BTG anti-proliferation factor 2

CTG

Cell Titer-Glo

Dcn

Decorin

DMEM

Dulbecco's modified eagle medium

EDTA

ethylenediaminetetraacetic acid

EGR

Early growth response 1

FITC

Fluorescein isothiocyanate

GAPDH

Glyceraldehyde-3-phosphate dehydrogenase

GO

Gene ontology

H\&E

Hematoxylin and eosin

HG-DMEM 
High glucose DMEM

IACUC

Institutional Animal Care and Use Committee

KEGG

Kyoto Encyclopedia of Genes and Genomes

LLLT

Low-level laser therapy

Mkx

Mohawk homeobox

MSCs

Mesenchymal stem cells

$N F-K B$

Nuclear factor kappa B

$\mathrm{Nr} 4 \mathrm{a} 1$

Nuclear receptor subfamily 4 group A member 1

OD

Optical density

PBS

Phosphate buffered saline

PFA

Paraformaldehyde

PPARY

Peroxisome proliferator activated receptor gamma

PTB

Photochemical tissue bonding

RhoA

Ras homolog family member $A$

RB

Rose Bengal

RNA-seq

RNA sequencing

ROS

reactive oxygen species

RT-PCR

Reverse Transcription-Polymerase Chain Reaction

Runx2

RUNX family transcription factor 2

RT

Room temperature

ScX 
Scleraxis

SD

Standard deviation

SD rat

Sprague-Dawley rat

SDS

Sodium dodecyl sulfate

SDS-PAGE

SDS polyacrylamide gel electrophoresis

Sox 9

SRY-box transcription factor 9

TDSC

Tendon-derived stem cells

TGF- $\beta$

Transforming growth factor- $\beta$

TNMD

Tenomodulin

\section{Declarations}

\section{Acknowledgments}

Not applicable.

\section{Authors' contributions}

TN, YHD and ML conceived and designed the experiments; ML and YMZ performed the experiments; QP and YHD contributed materials; QP, ML and YHD contributed data analysis; ML, YMZ wrote the manuscript and TN revised it. All authors read and approved the final manuscript.

\section{Funding}

This work was supported by Shanghai Municipal Key clinical specialty(shslczdzk00901), Shanghai Ninth People's Hospital cross funding (JYJC202101), and Shanghai Sailing Program (21YF1422800).

\section{Availability of data and materials}

The data and materials used in the current study are all available from the corresponding author upon reasonable request.

\section{Ethics approval and consent to participate}


All animal studies (including the rat euthanasia procedure) were carried out in compliance with the regulations and guidelines of Shanghai Jiao Tong University institutional animal care and conducted according to the AAALAC and the IACUC guidelines.

\section{Consent for publication}

Not applicable.

\section{Competing interests}

The authors declare that there are no competing interests.

\section{References}

1. Hodgins JL, Trofa DP, Donohue S, Littlefield M, Schuk M, Ahmad CS. Forearm Flexor Injuries Among Major League Baseball Players: Epidemiology, Performance, and Associated Injuries. The American journal of sports medicine. 2018;46(9):2154-60.

2. Lian $4 \leq$, Scott A, Engebretsen L, Bahr R, Duronio V, Khan K. Excessive apoptosis in patellar tendinopathy in athletes. The American journal of sports medicine. 2007;35(4):605-11.

3. Arnoczky SP, Lavagnino M, Egerbacher M. The mechanobiological aetiopathogenesis of tendinopathy: is it the over-stimulation or the under-stimulation of tendon cells? International journal of experimental pathology. 2007;88(4):217-26.

4. Im GI. Tissue Engineering in Osteoarthritis: Current Status and Prospect of Mesenchymal Stem Cell Therapy. BioDrugs : clinical immunotherapeutics, biopharmaceuticals and gene therapy. 2018;32(3):183-92.

5. Veronesi F, Della Bella E, Torricelli P, Pagani S, Fini M. Effect of adipose-derived mesenchymal stromal cells on tendon healing in aging and estrogen deficiency: an in vitro co-culture model. Cytotherapy. 2015;17(11):1536-44.

6. Schneider M, Angele P, Ju邓rvinen TAH, Docheva D. Rescue plan for Achilles: Therapeutics steering the fate and functions of stem cells in tendon wound healing. Advanced drug delivery reviews. 2018;129:352-75.

7. Lui PPY, Wong CM. Biology of Tendon Stem Cells and Tendon in Aging. Frontiers in genetics. 2019;10:1338.

8. Bian X, Liu T, Zhou M, He G, Ma Y, Shi Y, et al. Absence of estrogen receptor beta leads to abnormal adipogenesis during early tendon healing by an up-regulation of PPARHË Journal of cellular and molecular medicine. 2019;23(11):7406-16.

9. Lui PP, Wong OT, Lee YW. Transplantation of tendon-derived stem cells pre-treated with connective tissue growth factor and ascorbic acid in vitro promoted better tendon repair in a patellar tendon window injury rat model. Cytotherapy. 2016;18(1):99-112. 
10. Bensadoun RJ. Photobiomodulation or low-level laser therapy in the management of cancer therapyinduced mucositis, dermatitis and lymphedema. Current opinion in oncology. 2018;30(4):226-32.

11. Avci P, Gupta A, Sadasivam M, Vecchio D, Pam Z, Pam N, et al. Low-level laser (light) therapy (LLLT) in skin: stimulating, healing, restoring. Seminars in cutaneous medicine and surgery. 2013;32(1):4152.

12. Kennedy J, Verne S, Griffith R, Falto-Aizpurua L, Nouri K. Non-invasive subcutaneous fat reduction: a review. Journal of the European Academy of Dermatology and Venereology : JEADV. 2015;29(9):1679-88.

13. Tani A, Chellini F, Giannelli M, Nosi D, Zecchi-Orlandini S, Sassoli C. Red (635 nm), Near-Infrared (808 $\mathrm{nm}$ ) and Violet-Blue (405 nm) Photobiomodulation Potentiality on Human Osteoblasts and Mesenchymal Stromal Cells: A Morphological and Molecular In Vitro Study. International journal of molecular sciences. 2018. https://doi.org/10.3390/ijms19071946.

14. Zare F, Moradi A, Fallahnezhad S, Ghoreishi SK, Amini A, Chien S, et al. Photobiomodulation with 630

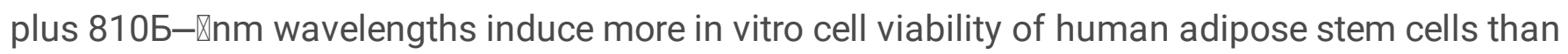
human bone marrow-derived stem cells. Journal of photochemistry and photobiology. B, Biology. 2019;201:111658.

15. Ni T, Senthil-Kumar P, Dubbin K, Aznar-Cervantes SD, Datta N, Randolph MA, et al. A photoactivated nanofiber graft material for augmented Achilles tendon repair. Lasers Surg Med. 2012;44(8):645-52.

16. Yao ZC, Wang $x$, Zhang W, Liu YS, Ni T. Photochemical tissue bonding promotes the proliferation and migration of injured tenocytes through ROS/RhoA/NF-kappaB/Dynamin 2 signaling pathway. J Cell Physiol. 2018;233(10):7047-56.

17. Yang G, Rothrauff BB, Tuan RS. Tendon and ligament regeneration and repair: clinical relevance and developmental paradigm. Birth defects research. Part C, Embryo today : reviews. 2013;99(3):203-22.

18. Voleti PB, Buckley MR, Soslowsky LJ. Tendon healing: repair and regeneration. Annual review of biomedical engineering. 2012;14:47-71.

19. Akamatsu FE, Saleh SO, Teodoro WR, da Silva AQ, Martinez CAR, Duarte RJ, et al. Experimental model of Achilles tendon injury in rats. Acta Cir Bras. 2014;29(7):417-22.

20. Lui PPY, Chan KM. Tendon-derived stem cells (TDSCs): from basic science to potential roles in tendon pathology and tissue engineering applications. Stem Cell Rev Rep. 2011;7(4):883-97.

21. Qin DD, Yang YF, Pu ZQ, Liu D, Yu C, Gao P, et al. NR4A1 retards adipocyte differentiation or maturation via enhancing GATA2 and p53 expression. J Cell Mol Med. 2018;22(10):4709-20.

22. Palumbo-Zerr K, Zerr P, Distler A, Fliehr J, Mancuso R, Huang JG, et al. Orphan nuclear receptor NR4A1 regulates transforming growth factor-beta signaling and fibrosis. Nat Med. 2015;21(2):15058.

23. Tabakoglu HO, Sani MM, Uba Al, Abdullahi UA. Assessment of circular wound healing in rats after exposure to 808-nm laser pulses during specific healing phases. Lasers in surgery and medicine. 2016;48(4):409-15. 
24. Aihara N, Yamaguchi M, Kasai K. Low-energy irradiation stimulates formation of osteoclast-like cells via RANK expression in vitro. Lasers Med Sci. 2006;21(1):24-33.

25. Altan BA, Sokucu O, Ozkut MM, Inan S. Metrical and histological investigation of the effects of lowlevel laser therapy on orthodontic tooth movement. Lasers Med Sci. 2012;27(1):131-40.

26. Kuffler DP. Photobiomodulation in promoting wound healing: a review. Regenerative medicine. 2016;11(1):107-22.

27. Liu C, Luo JW, Zhang KK, Lin LX, Liang T, Luo ZP, et al. Tendon-Derived Stem Cell Differentiation in the Degenerative Tendon Microenvironment. Stem cells international. 2018. https://doi.org/10.1155/2018/2613821.

28. Murchison ND, Price BA, Conner DA, Keene DR, Olson EN, Tabin CJ, et al. Regulation of tendon differentiation by scleraxis distinguishes force-transmitting tendons from muscle-anchoring tendons. Development (Cambridge, England). 2007;134(14):2697-708.

29. Liu H, Zhu S, Zhang C, Lu P, Hu J, Yin Z, et al. Crucial transcription factors in tendon development and differentiation: their potential for tendon regeneration. Cell and tissue research. 2014;356(2):287-98.

30. Wu L, Amarachintha S, Xu J, Oley F, Du W. Mesenchymal COX2-PG secretome engages NR4A-WNT signalling axis in haematopoietic progenitors to suppress anti-leukaemia immunity. British journal of haematology. 2018;183(3):445-56.

31. Freire PR, Conneely OM. NR4A1 and NR4A3 restrict HSC proliferation via reciprocal regulation of C/EBPalpha and inflammatory signaling. Blood. 2018;131(10):1081-93.

32. Yang YF, Xie FY, Qin DD, Zong C, Han F, Pu ZQ, et al. The orphan nuclear receptor NR4A1 attenuates oxidative stress-induced beta cells apoptosis via up-regulation of glutathione peroxidase 1. Life Sci. 2018;203:225-32.

33. Shi X, Ye H, Yao X, Gao Y. The involvement and possible mechanism of NR4A1 in chondrocyte apoptosis during osteoarthritis. American journal of translational research. 2017;9(2):746-54.

34. Hu C, Zhang Y, Tang K, Luo Y, Liu Y, Chen W. Downregulation of CITED2 contributes to TGFHXmediated senescence of tendon-derived stem cells. Cell and tissue research. 2017;368(1):93-104.

35. Chen L, Jiang C, Tiwari SR, Shrestha A, Xu P, Liang W, et al. TGIF1 Gene Silencing in Tendon-Derived Stem Cells Improves the Tendon-to-Bone Insertion Site Regeneration. Cellular physiology and biochemistry : international journal of experimental cellular physiology, biochemistry, and pharmacology. 2015;37(6):2101-14.

36. Maeda T, Sakabe T, Sunaga A, Sakai K, Rivera AL, Keene DR, et al. Conversion of mechanical force into TGF-H囚-mediated biochemical signals. Current biology : CB. 2011;21(11):933-41.

37. Igarashi Y, Chosa N, Sawada S, Kondo H, Yaegashi T, Ishisaki A. VEGF-C and TGF-H囚 reciprocally regulate mesenchymal stem cell commitment to differentiation into lymphatic endothelial or osteoblastic phenotypes. International journal of molecular medicine. 2016;37(4):1005-13.

\section{Tables}


Table1 Primer sequences $\left(5^{\prime}-3^{\prime}\right)$ used in real time RT-PCR.

\begin{tabular}{|c|c|}
\hline Gene & Primer sequences \\
\hline \multirow[t]{2}{*}{ Scx } & Forward AACACGGCCTTCACTGCGCTG \\
\hline & Reverse CAGTAGCACGTTGCCCAGGTG \\
\hline \multirow[t]{2}{*}{ Tnmd } & Forward CCAGACAAGCAAGCGAGGA \\
\hline & Reverse AАСТTCСТATTAGACTCTCC \\
\hline \multirow[t]{2}{*}{ Mkx } & Forward AGTGGCTTTACAAGCACCGT \\
\hline & Reverse ACACTGAGCCGCTCGGCGTT \\
\hline \multirow[t]{2}{*}{ Den } & Forward TTGCAGGGAATGAAGGGTCT \\
\hline & Reverse TGTGGGTGAATTTGCCAATA \\
\hline \multirow[t]{2}{*}{ GADPH } & Forward ACAGCAACAGGGTGGTGGAC \\
\hline & Reverse TTTGAGGGTACAGCGAACTT \\
\hline \multirow[t]{2}{*}{ PPARY } & Forward CGGCGATCTTGACAGGAAAG \\
\hline & Reverse GCTTCCACGGATCGAAACTG \\
\hline \multirow[t]{2}{*}{ sox9 } & Forward AGAGCGTTGCTCGGAACTGT \\
\hline & Reverse TCCTGGACCGAAACTGGTAAA \\
\hline \multirow[t]{2}{*}{ RUNX2 } & Forward CCGATGGGACCGTGGTT \\
\hline & Reverse CAGCAGAGGCATTTCGTAGCT \\
\hline \multirow[t]{2}{*}{$\mathrm{Nr} 4 \mathrm{a} 1$} & Forward ATGCGATTCTGCAGCTCTTCC \\
\hline & Reverse GGGTGGTATTGTCGTAGTAGAAGG \\
\hline
\end{tabular}

\section{Figures}


a

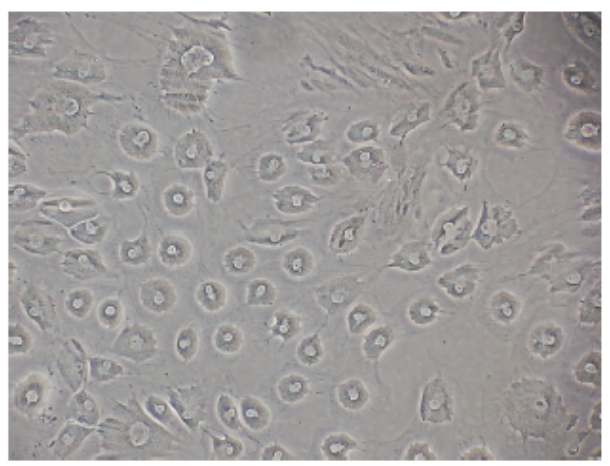

b

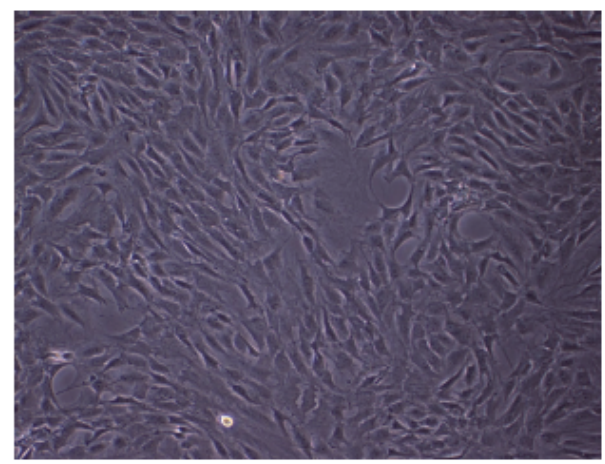

e

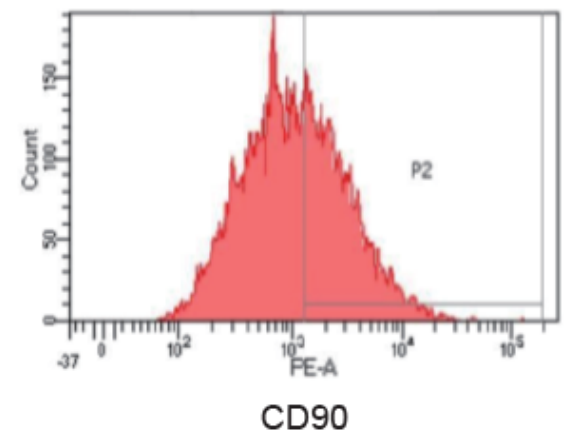

CD90

Figure 1

(a.b) Morphological characteristics of TDSCs and identification by flow cytometry. (c-e) Morphological characteristics of TDSCs from generation 0 and 3 . Identification of TDSCs by flow cytometry for CD44, CD90 (positive markers), and CD45 (negative marker).

a

\section{.}
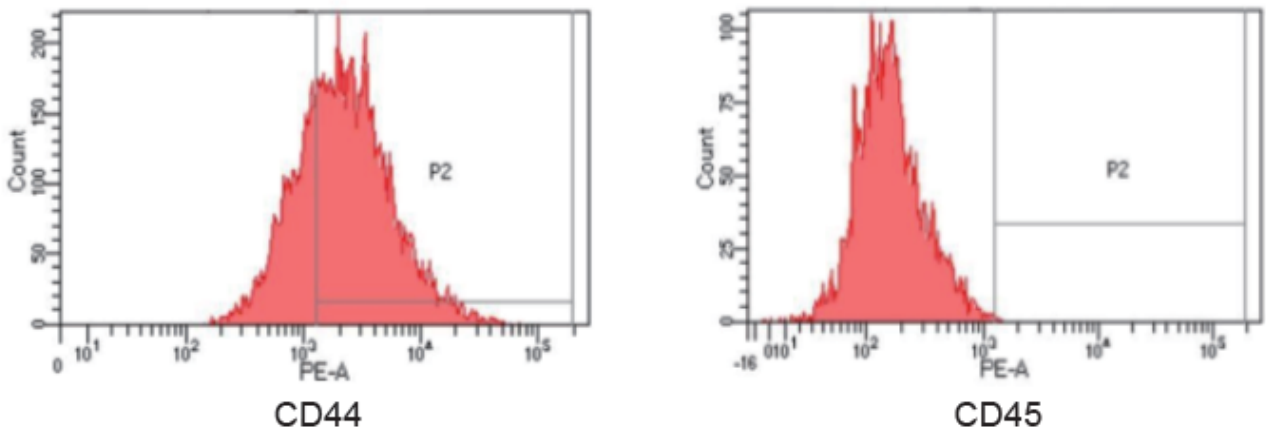

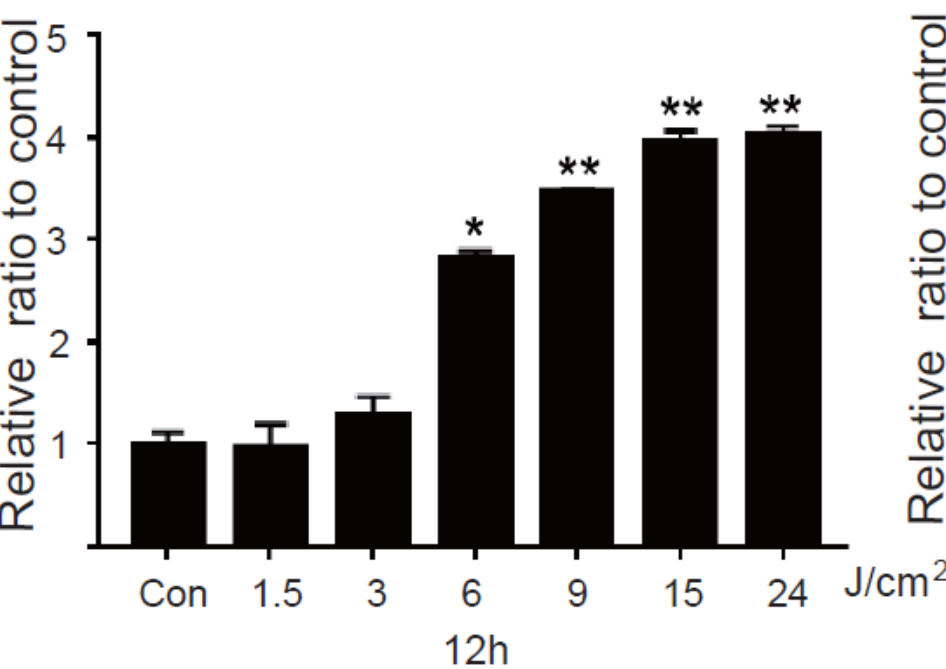

b

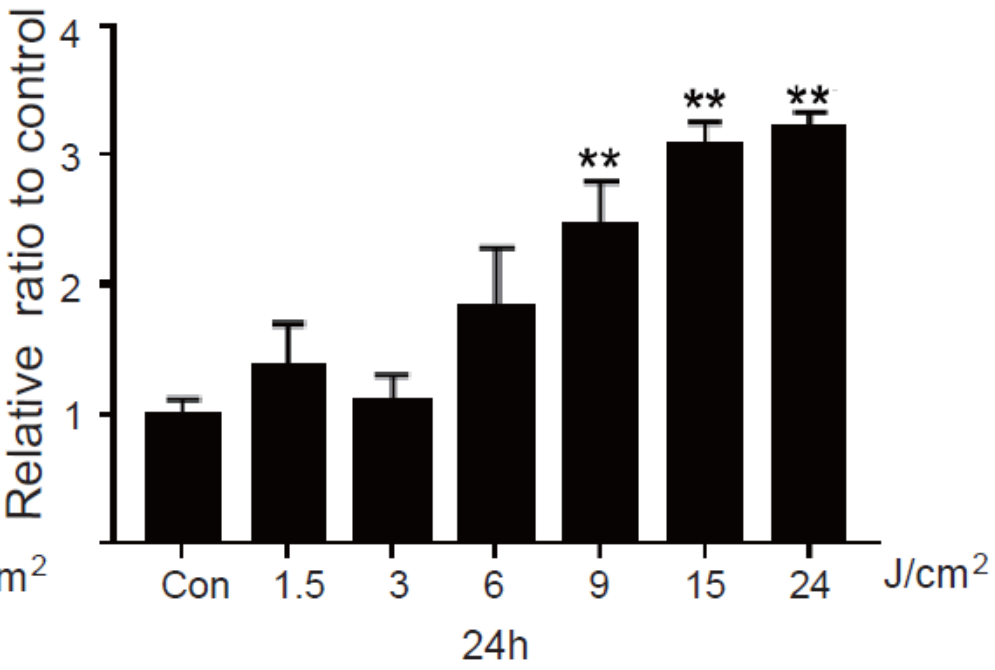

Figure 2 
Effects of $532 \mathrm{~nm}$ laser with different energy density on cell viability of TDSCs. (a) Cell viability of TDSCs was detected by CTG after 24h of laser intervention with $532 \mathrm{~nm}\left(n=6,{ }^{*} P<0.05, * * P<0.01\right)$. (b) Cell viability of TDSCs was detected by CTG after $48 \mathrm{~h}$ of laser intervention with $532 \mathrm{~nm}\left(n=6,{ }^{*} P<0.05, \star \star P<\right.$ $0.01)$.

a
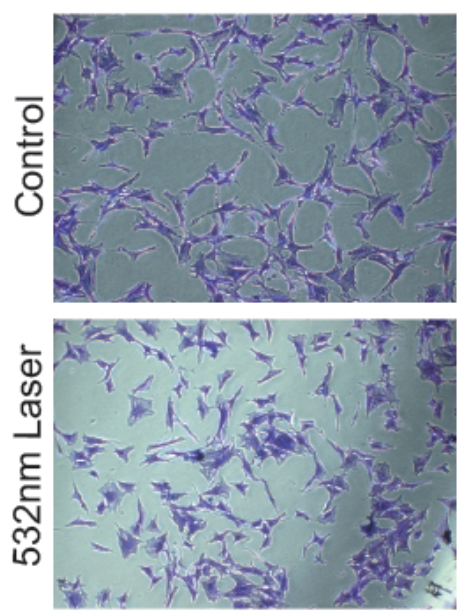

$6 h$
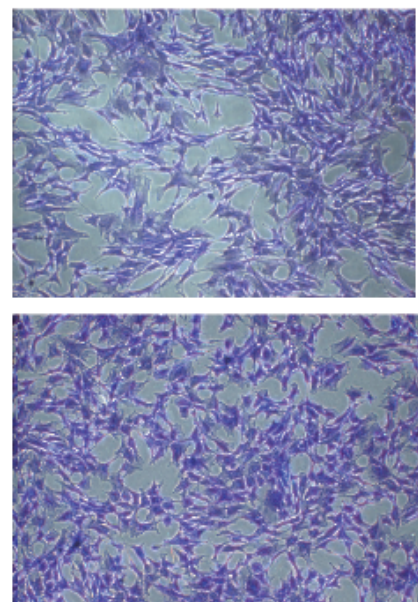

$12 \mathrm{~h}$
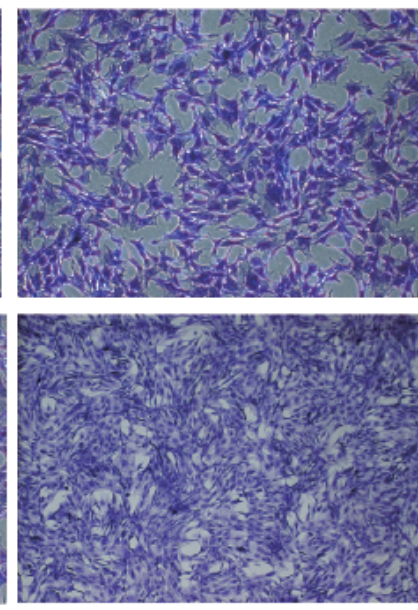

$24 \mathrm{~h}$ b

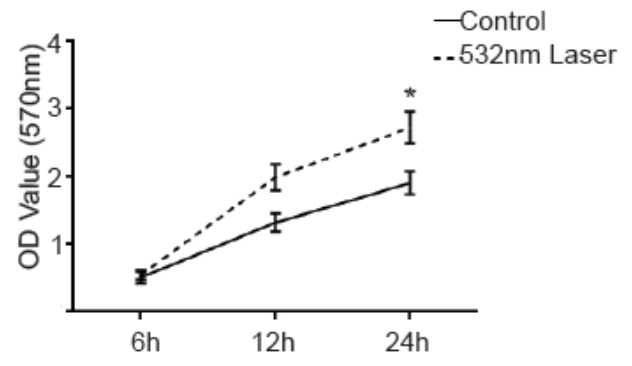

\section{Figure 3}

Effects of $532 \mathrm{~nm}$ laser on the proliferation of TDSCs. (a) The TDSCs of the control group and the 532 $\mathrm{nm}$ laser group were compared at $6 \mathrm{~h}, 12 \mathrm{~h}$, and $24 \mathrm{~h}$ by crystal violet staining. (b) The OD value of each group was detected, and the cell proliferation was quantitatively compared $(n=6, * P<0.05)$. 
a
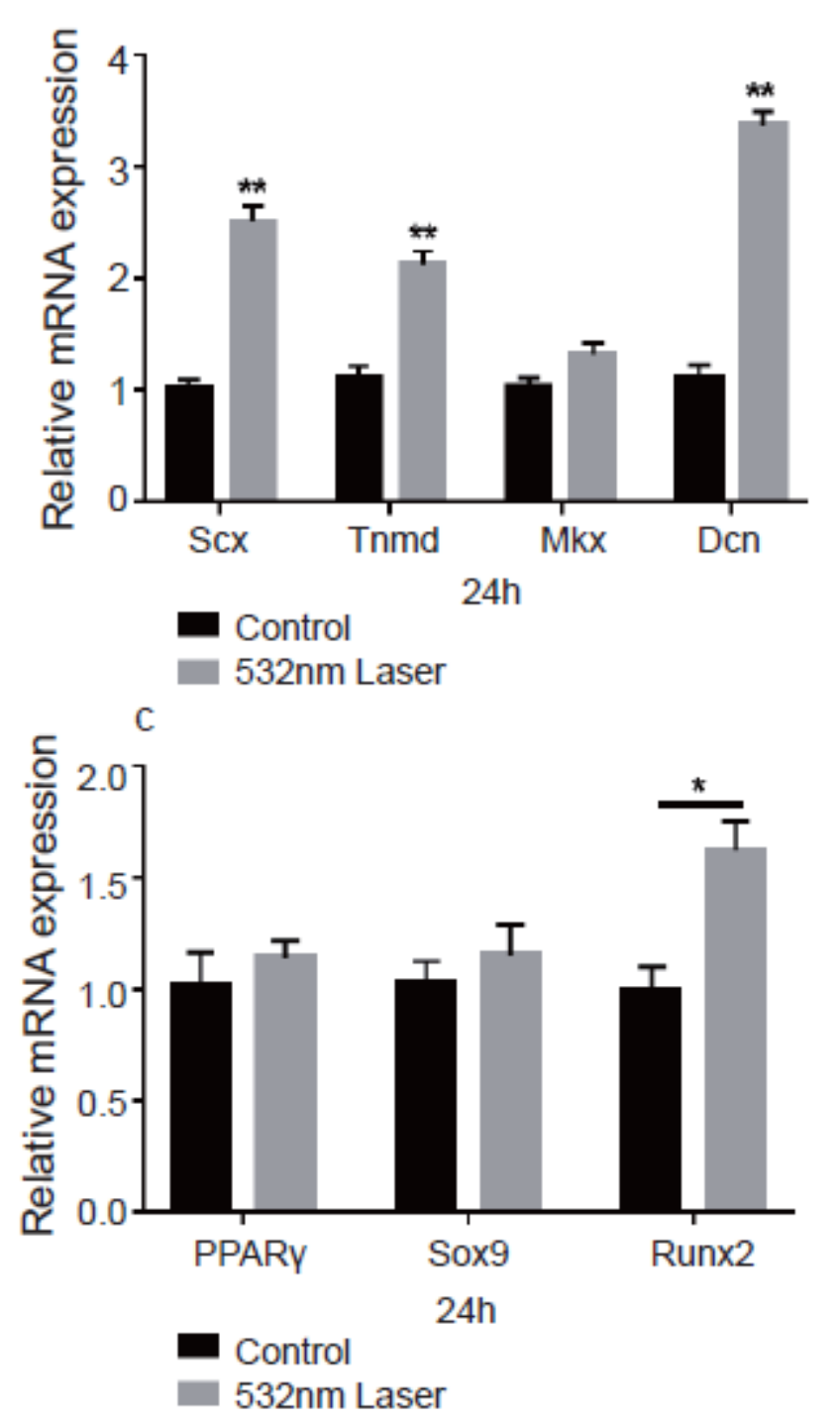
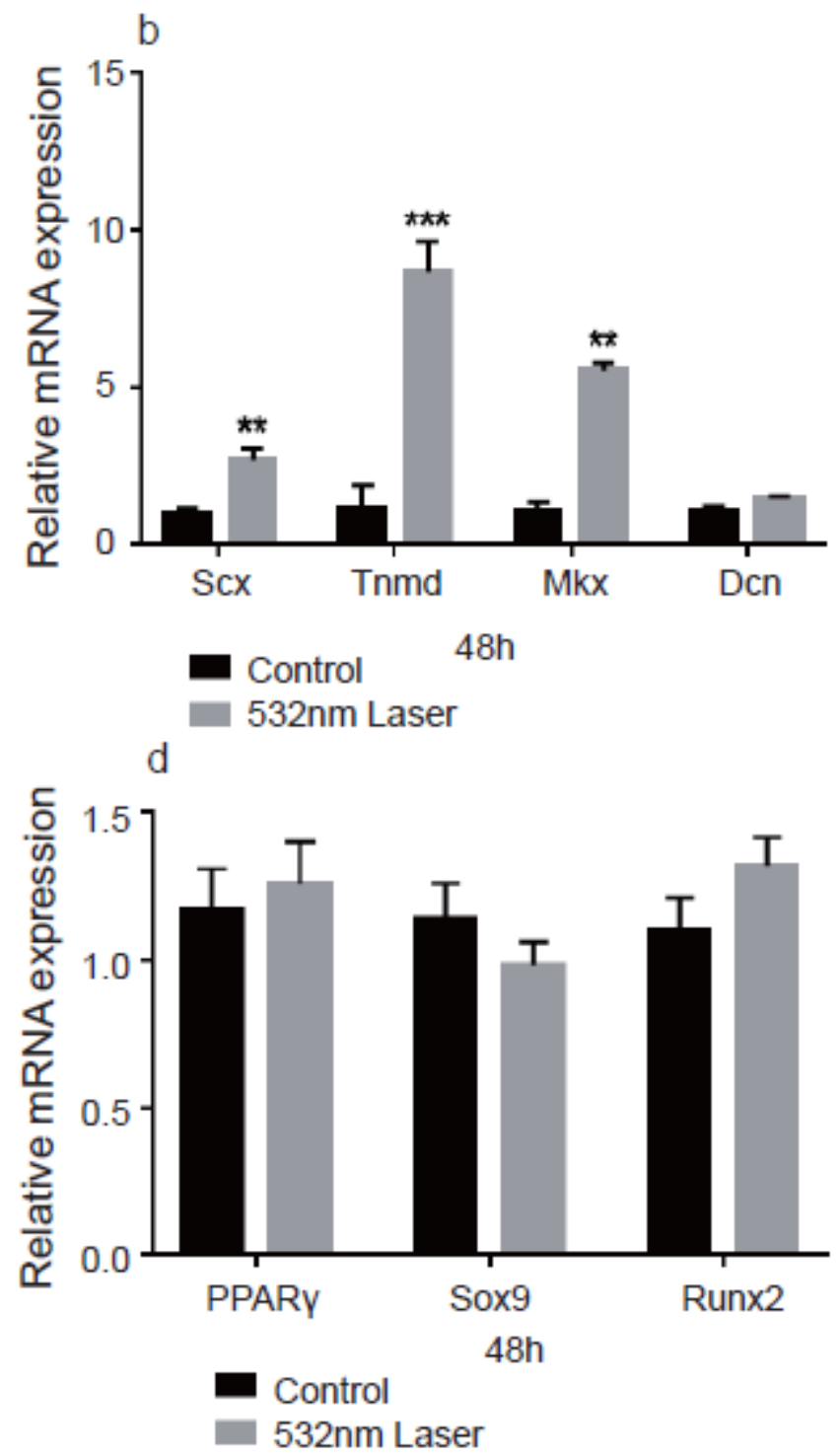

Figure 4

Effects of $532 \mathrm{~nm}$ laser on differentiation of TDSCs. (a) The expression of tenogenic differentiation markers of TDSCs after $24 \mathrm{~h}$ of TDSCs intervention with $532 \mathrm{~nm}$ laser $(n=6, * * P<0.01)$. (b) The expression of tenogenic differentiation markers of TDSCs after $24 \mathrm{~h}$ of TDSCs intervention with $532 \mathrm{~nm}$ laser ( $\mathrm{n}=6$, $\star * P<0.01 \nabla * * *<0.001)$. (c) The expression of adipogenic differentiation, chondrogenic differentiation, and osteogenic differentiation markers of TDSCs after $24 \mathrm{~h}$ of TDSCs intervention by $532 \mathrm{~nm}$ laser ( $\mathrm{n}=6$, $\left.{ }^{*} \mathrm{P}<0.05\right)$. (d) The expression of adipogenic differentiation, chondrogenic differentiation, and osteogenic differentiation markers of TDSCs after $48 \mathrm{~h}$ of TDSCs intervention by $532 \mathrm{~nm}$ laser. 

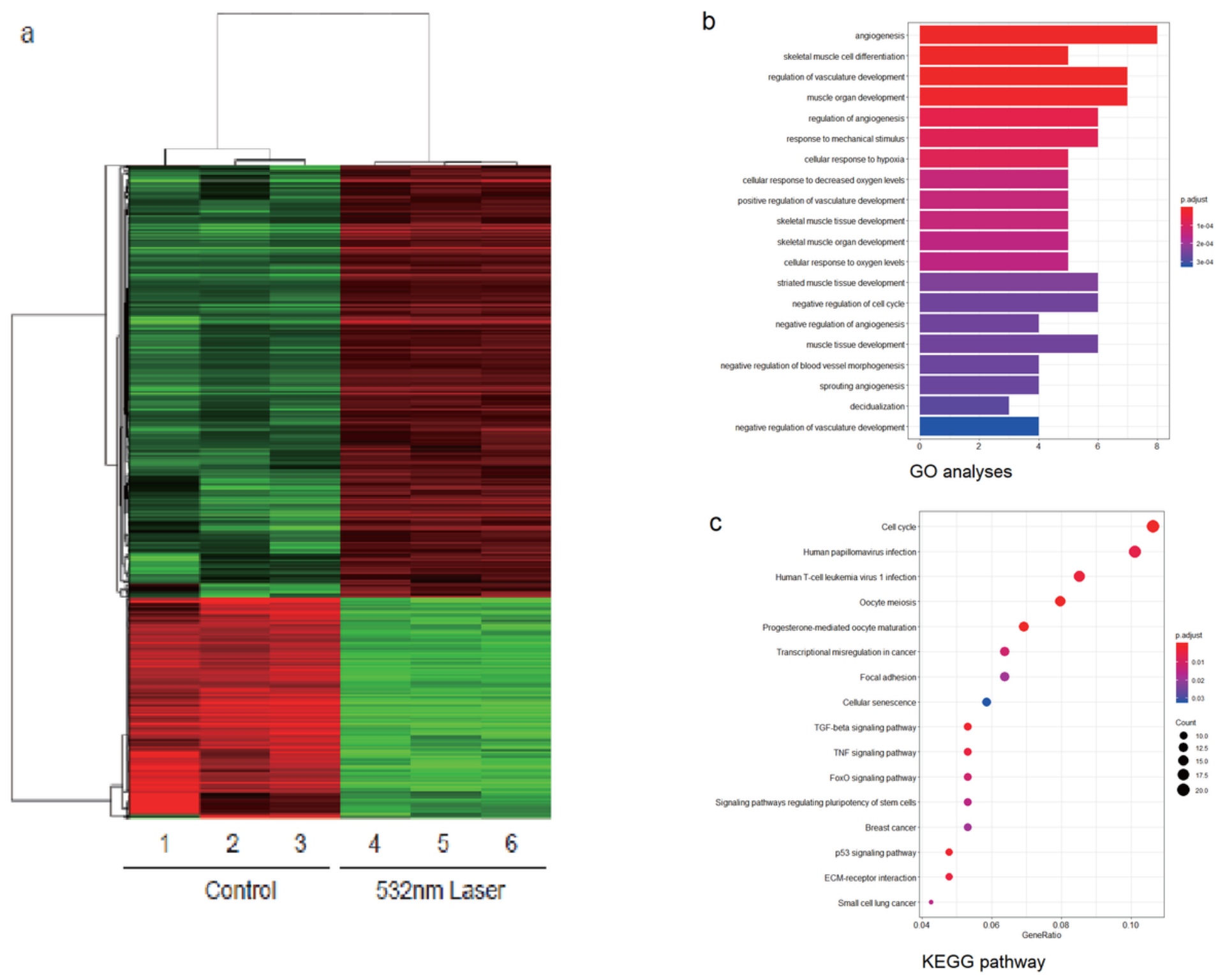

\section{Figure 5}

Gene expression profile of Rat Achilles tendon tissue. (a) Results of gene chip microarray in the control group and $532 \mathrm{~nm}$ laser group. (b) The top 20 biological processes enriched in the up-regulated genes by GO analysis of up-regulated genes. (c) The top 20 canonical pathways enriched in the up-regulated genes by KEGG pathway analysis. 


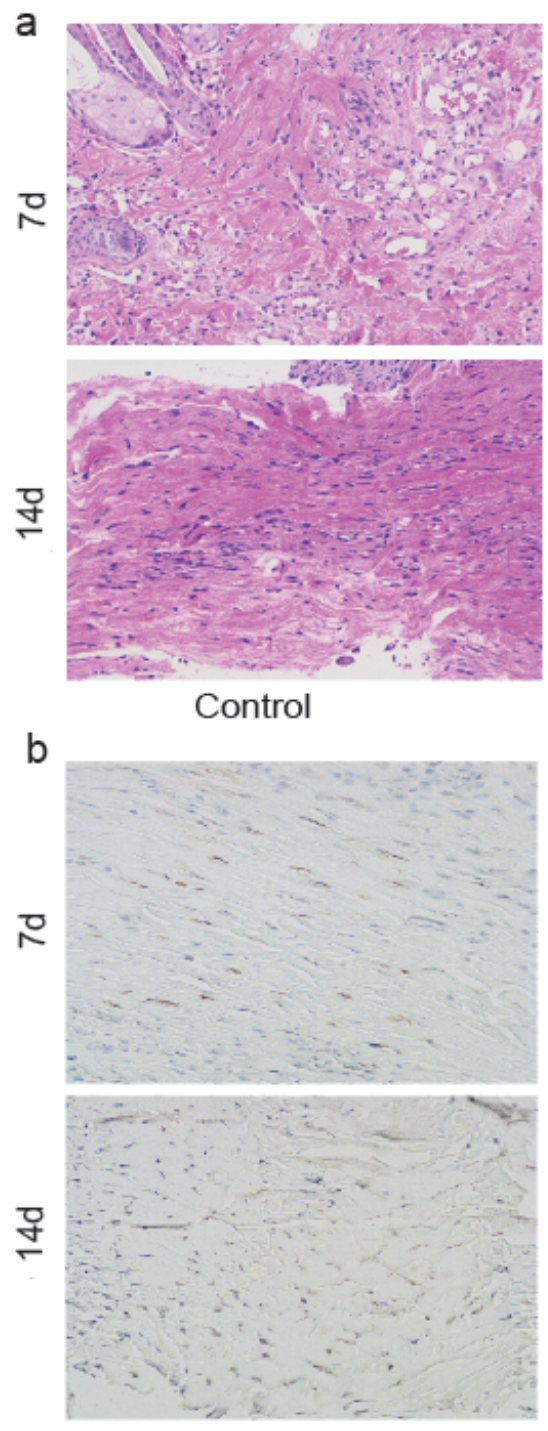

Control
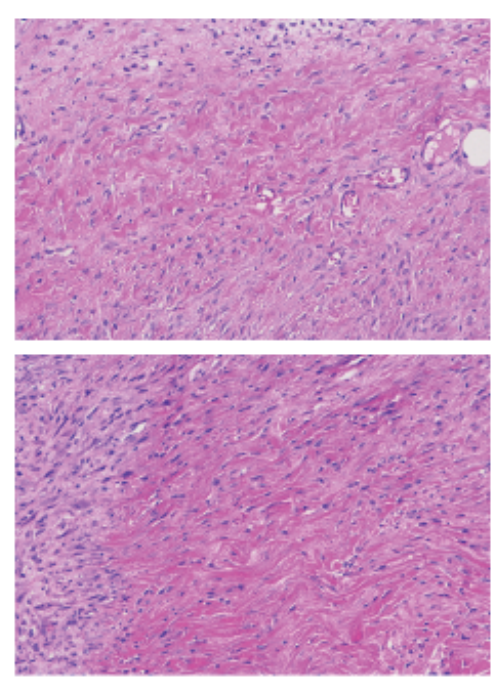

$532 \mathrm{~nm}$ Laser
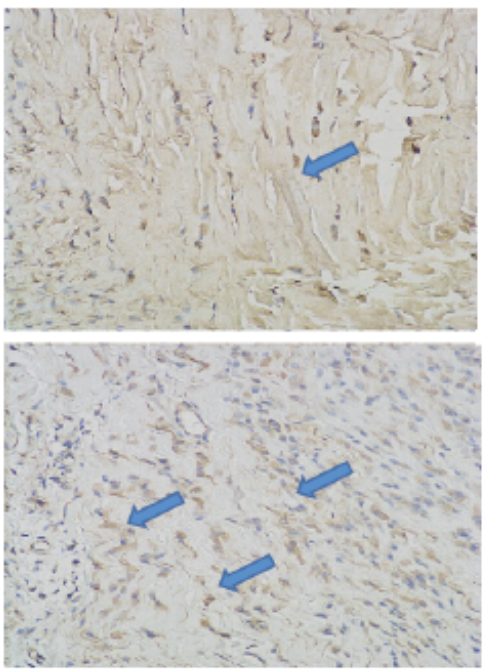

$532 \mathrm{~nm}$ Laser

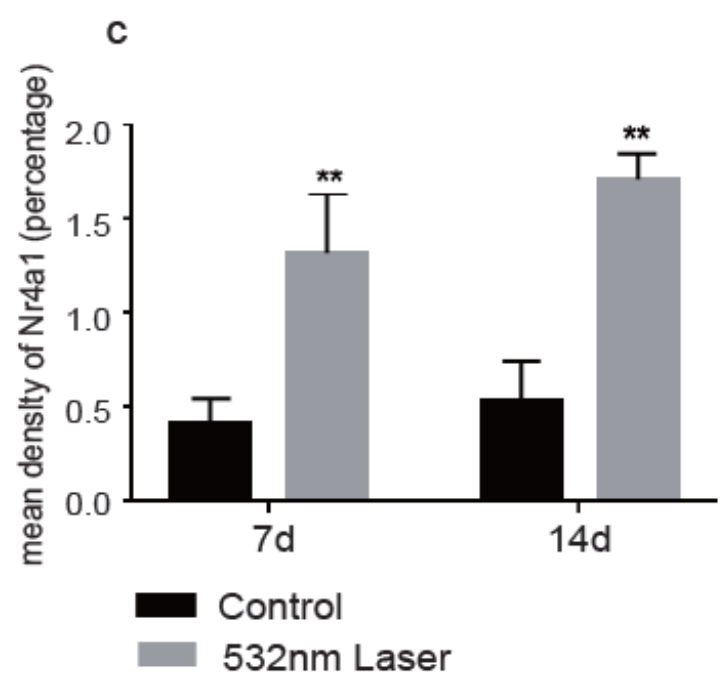

\section{Figure 6}

The expression of Nr4a1 in Achilles tendon tissue of rats. (a) The repair of the injured Achilles tendon in the control group and $532 \mathrm{~nm}$ laser group was observed by HE staining, x200 (b) The expression of Nr4a1 was detected by immunohisto chemistry in human samples. x200. (c) A significant difference in Nr4a1 expression level between control group and the $532 \mathrm{~nm}$ laser group $(n=3, * * P<0.01)$. 
a

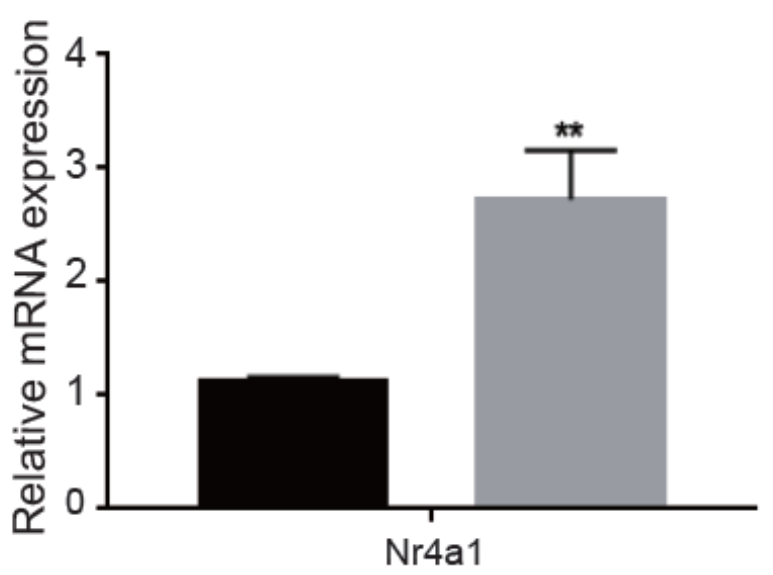

C

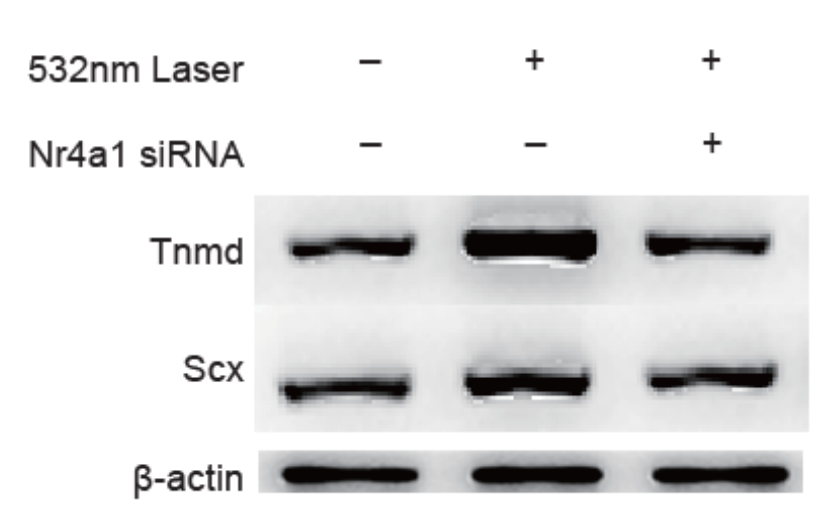

b

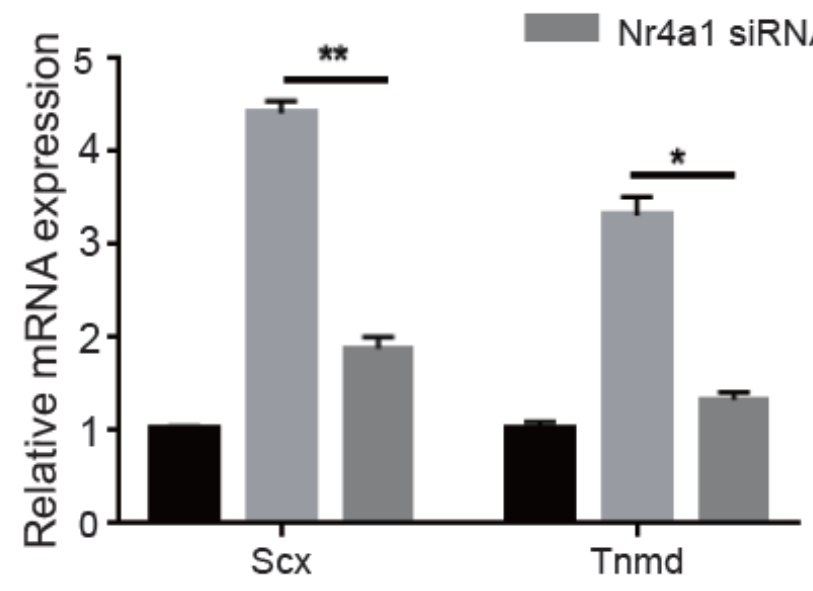

d

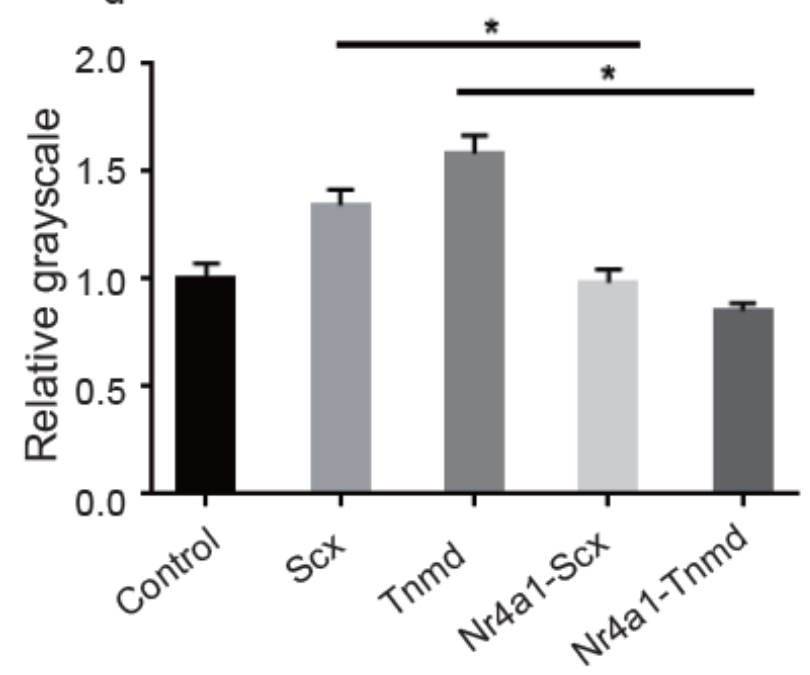

Figure 7

Nr4a1 inhibition by siRNA influences the expression of tenogenic differentiation markers of TDSCs. (a) Nr4a1 was highly expressed in TDSCs after $532 \mathrm{~nm}$ laser intervention $(n=6, * * P<0.01)$. (b) The RT-PCR analysis of the mRNA levels of Scx, Tnmd expression in TDSCs $(n=6, * P<0.05, * * P<0.01)$. (c) Western blot analysis of the protein levels of expression Scx, Tnmd expression in TDSCs. (d) The grayscale value of the strip was detected, and the expressions of $S c x$ and Tnmd were quantitatively analyzed $(n=3, * P<0.05)$. 